\title{
Postpartum glucose tolerance status 6 to 12 weeks after gestational diabetes mellitus: a Brazilian cohort
}

\author{
Reavaliação do estado glicêmico 6 a 12 semanas após \\ o diabetes melito gestacional: uma coorte brasileira
}

Letícia Schwerz Weinert' ${ }^{1}$ Livia Silveira Mastella' ${ }^{1}$

Maria Lúcia Rocha Oppermann ${ }^{2,3}$, Sandra Pinho Silveiro, ${ }^{1,2,4}$,

Luciano Santos Pinto Guimarães ${ }^{5}$, Angela Jacob Reichelt ${ }^{4}$

\begin{abstract}
Objectives: The aims of this study were to estimate the local rate of postpartum diabetes screening after gestational diabetes mellitus (GDM) pregnancies, and to identify clinical variables associated with retesting rates and with the persistence of decreased glucose tolerance. Subjects and methods: Prospective cohort of GDM women with prenatal delivery at a specialized center, from November 2009 to May 2012. All women were advised to schedule a 6 weeks postpartum 75-g oral glucose tolerance test (OGTT). Results: Of the 209 women included, 108 (51.7\%) returned to be tested with fasting plasma glucose $(n=14)$, OGTT $(n=93)$ or random glucose $(n=1)$. Return was associated with lower parity rate $(2 \mathrm{vs.} 3, \mathrm{p}<0.001)$ and higher pregnancy 2 -h OGTT (165 vs. $155 \mathrm{mg} / \mathrm{dL}, \mathrm{p}=0.034)$, but not with socio-demographic characteristics. Four women $(3.7 \%)$ had diabetes, $22(20.4 \%)$ had impaired fasting glucose or impaired glucose tolerance. Persistent hyperglycemia was associated with a positive family history of diabetes (relative risk - RR $2.41, p=0.050$ ), diagnostic 2 -h OGTT in pregnancy (RR 1.01, $p=0.045$ ), insulin use during pregnancy ( $R R 2.37, p=0.014)$, and cesarean section (RR 2.61, $p=0.015$ ). Conclusions: Even though postpartum abnormalities were frequent in GDM, rates of postpartum diabetes screening were undesirably low. As no specific clinical profile defines who will adhere to postpartum testing, it is essential to encourage all women to reevaluate their glucose status, particularly those with a family history of diabetes and more severe hyperglycemia. Arq Bras Endocrinol Metab. 2014;58(2):197-204
\end{abstract}

\section{Keywords}

Gestational diabetes; postpartum testing; GDM; type 2 diabetes; oral glucose tolerance test

\section{RESUMO}

Objetivos: Os objetivos foram estimar a taxa de reavaliação de diabetes pós-parto em mulheres com diabetes melito gestacional (DMG) e identificar fatores associados ao retorno e à persistência das alterações glicêmicas. Sujeitos e métodos: Coorte prospectiva de mulheres com DMG atendidas em ambulatório de pré-natal especializado, de novembro de 2009 a maio de 2012. Todas foram orientadas a agendar o teste oral de tolerância à glicose (TOTG) a partir da sexta semana pós-parto. Resultados: Das 209 mulheres arroladas na gestação, 108 (51,7\%) foram avaliadas após o parto: 14 com glicemia de jejum, 93 com o TOTG e uma com glicemia ao acaso. 0 retorno para reavaliação foi associado com menor paridade $(2$ vs. $3, \mathrm{p}<0,001)$ e com glicemia de 2-h mais elevada noTOTG diagnóstico (165 vs. $155 \mathrm{mg} / \mathrm{dL}, \mathrm{p}=0,034$ ). Diabetes foi diagnosticado em quatro mulheres $(3,7 \%) \mathrm{e}$ pré-diabetes em $22(20,4 \%)$. Análise multivariada evidenciou que a história familiar de diabetes (risco relativo - $R R 2,41, p=0,050$ ), a glicemia de 2 horas noTOTG da gestação ( $R R$ 1,01, $p=0,045$ ), o uso de insulina na gestação (RR 2,37, $p=0,014$ ) e a taxa de cesariana ( $R R 2,61, p=0,015$ ) foram os fatores associados à persistência da hiperglicemia. Conclusões: 0 retorno para reavaliação foi baixo, embora as alterações glicêmicas tenham sido frequentes. Como não houve fatores que indiquem quais mulheres retornarão, estratégias para aumentar a adesão são necessárias, especialmente quando há história familiar ou o DMG foi mais grave. Arq Bras Endocrinol Metab. 2014;58(2):197-204

Descritores

Diabetes gestacional; reavaliação pós-parto; DMG; diabetes tipo 2; teste oral de tolerância à glicose
1 Programa de Pós-graduação em Endocrinologia, Universidade Federal do Rio Grande do Sul (UFRGS), Porto Alegre, RS, Brazil 2 Faculdade de Medicina, UFRGS, Porto Alegre, RS, Brazil ${ }^{3}$ Serviço de Ginecologia e Obstetrícia, Hospital de Clínicas de Porto Alegre (HCPA), Porto Alegre, RS, Brazil ${ }^{4}$ Serviço de Endocrinologia, HCPA, Porto Alegre, RS, Brazil ${ }^{5}$ Unidade de Bioestatística, HCPA, Porto Alegre, RS, Brazil
Correspondence to: Angela Jacob Reichelt Serviço de Endocrinologia, Hospital de Clínicas de Porto Alegre Rua Ramiro Barcelos, 2350, prédio $12,4^{\circ}$ andar 90035-052 - Porto Alegre, RS, Brazil areichelt@hcpa.ufrgs.br

Received on Oct/16/2013 Accepted on Nov/7/2013 


\section{INTRODUCTION}

$\mathrm{T}$ he prevalence of gestational diabetes mellitus (GDM) is increasing in parallel with higher rates of obesity and type 2 diabetes, as well as with more inclusive diagnostic criteria intended to be used worldwide; rates of almost $20 \%$ are described in some peculiar settings (1-3). Women with GDM are at increased risk of developing type 2 diabetes (4) or pre-diabetes in the follow-up, and should have a postpartum evaluation in order to disclose persistent alterations of glucose metabolism, either by performing an oral glucose tolerance test (OGTT) or fasting plasma glucose $(5,6)$. Rates of return after postpartum vary across studies, ranging from as low as $3.4 \%$ after routine care advice in the three month postpartum period, to a rate as high as $92.6 \%$ with active reminder strategies, as described in a recent systematic review including 54 studies (7).

A number of clinical characteristics are related both to the return for reevaluation and to postpartum glucose alterations, such as age, race, social parameters, and labelling patients as GDM carriers at postpartum discharge from hospital in a large series (8). The use of medication, either insulin (8-11) or oral agents (8) for glycemic control during pregnancy, is associated with persistent hyperglycemia, whereas body mass index $(B M I)(10)$, race $(9,11)$ and other risk factors (1-h blood glucose in diagnostic OGTT (11), previous GDM (9), parity rates (10)) are described in other studies.

Rates of pre-diabetes or diabetes after GDM may vary according to different methods and criteria used to define glucose alteration, to the postpartum time elapsed since pregnancy, and to clinical characteristics of the study population. A wide range of postpartum glycemic alterations are described: from $1.1 \%$ to $25.3 \%$ for diabetes, and from $2.2 \%$ to $42.3 \%$ for both impaired glucose tolerance and impaired fasting glycemia (7).

The aims of this study were to estimate the rate of postpartum diabetes screening in pregnancies complicated by GDM and treated at a reference outpatient clinic, to identify clinical variables associated with postpartum testing, and to describe the characteristics related to persistent postpartum hyperglycemia.

\section{SUBJECTS AND METHODS}

All women with GDM whose pregnancy prenatal care was carried out at a specialized outpatient clinic from November 2009 to May 2012 were included. The university hospital delivers tertiary care to Brazilian public health system patients. The outpatient clinic includes a multidisciplinary prenatal care with regular appointments with an obstetrician, an endocrinologist, a nutritionist and a nurse.

All subjects were interviewed by one of the authors (LSW). They answered a structured questionnaire that included socio-demographic characteristics, past and present medical history, and current pregnancy information. Physical examination was performed to evaluate height, weight, blood pressure and obstetric parameters. All women were followed up until delivery. At the discharge from the hospital they were instructed to schedule a 75-g OGTT 6 and 12 weeks after delivery, according to official recommendations $(5,6)$. Medical data on delivery and the newborn(s) were retrieved from hospital records. All participants signed an informed written consent, and the hospital ethical committee approved the study protocol.

Until the end of 2010, diagnosis of GDM followed the recommendations of the $2^{a}$ Reunião do Grupo de Trabalho em Diabetes e Gestação ( $2^{\text {th }}$ Meeting of The Diabetes and Pregnancy Task Force) (12): after a positive screening (fasting plasma glucose $-\mathrm{FPG}-\geq 85$ $\mathrm{mg} / \mathrm{dL}$ ), a 75 -g OGTT was performed and GDM was diagnosed if fasting plasma glucose $\geq 110 \mathrm{mg} / \mathrm{dL}$, or 2 -h plasma glucose $\geq 140 \mathrm{mg} / \mathrm{dL}$. After the release of the International Association of Diabetes and Pregnancy Study Groups (IADPSG) recommendation (13) and its adoption by the American Diabetes Association (6), women with fasting plasma glucose $\geq 92 \mathrm{mg} / \mathrm{dL}$ or $\mathrm{l}$-h plasma glucose $\geq 180 \mathrm{mg} / \mathrm{dL}$, or 2 -h plasma glucose $\geq$ $153 \mathrm{mg} / \mathrm{dL}$ in the 75 -g OGTT were included.

The following information was collected: maternal age, self-reported skin color (white or dark skin tone), marital status, work outside home, socioeconomic status (14), years of study, parity, self-reported pre-pregnancy weight, active smoking at registration, chronic diseases, regular use of medicines and supplements, previous GDM, gestational hypertension, preeclampsia or eclampsia, or a macrosomic newborn. Height was measured at the first prenatal visit and blood pressure was recorded at all prenatal visits. Data on maternal weight gain, delivery route and medical emergencies were extracted from medical records. The Alc test, lipid profile, fasting insulin and C-peptide were measured at the third trimester in addition to routine prenatal evaluation. Insulin and C-peptide were measured only in non-insulin users at the time of blood sampling. BMI was calculated using the informed pre-gestational 
weight, with the equation weight $(\mathrm{kg}) /$ height $\left(\mathrm{m}^{2}\right)$. Preeclampsia was defined as blood pressure $\geq 140 / 90$ $\mathrm{mmHg}$ detected after the $20^{\text {th }}$ gestational week with significant proteinuria and gestational hypertension in the absence of significant proteinuria (15). Insulin resistance was evaluated by the homeostasis model assessment (HOMA-IR), and was calculated as: glucose in $\mathrm{mg} / \mathrm{dL} \times 0.0555 \times$ insulin/22.5 (16); a value $>4.31$ (the population specific $75^{\text {th }}$ percentile) was defined as insulin resistance.

\section{Outcomes}

The primary outcome was the diagnosis of postpartum pre-diabetes (impaired fasting glucose (IFG): FPG 100$125 \mathrm{mg} / \mathrm{dL}$; impaired glucose tolerance (IGT) 2-h plasma glucose in the 75-g OGTT $140-199 \mathrm{mg} / \mathrm{dL}$ ) or diabetes (FPG $\geq 126 \mathrm{mg} / \mathrm{dL}$ or 2 -h plasma glucose $\geq$ $200 \mathrm{mg} / \mathrm{dL}$ in the OGTT, or random plasma glucose $\geq$ $200 \mathrm{mg} / \mathrm{dL}$ ) (6). Additionally, we evaluated the rate of return after the postpartum, and the time elapsed since parturition, as well as clinical characteristics related to return and maintenance of hyperglycemia.

\section{Laboratory tests}

Glucose was measured by enzymatic colorimetric assays, HbAlc by high performance liquid chromatography (Variant II, BioRad Laboratories, Hercules, CA), and fasting insulin and C-peptide by chemiluminescence (Advia Centaur XP, Siemens Healthcare, Erlangen, Germany).

\section{Statistical analysis}

Descriptive statistics were used to present clinical and demographic variables of returning and non-returning women, and for those who remained hyperglycemic or not. Absolute and relative frequencies, means and standard deviation, and median and inter-quartile intervals were used as appropriate.

Differences in the distribution of categorical variables were analyzed with the chi-square test. The Shapiro-Wilk test was used to verify if continuous variables were normally distributed. Parametric continuous variables were evaluated with the T-test, and non-parametric ones with the Mann-Whitney test.

Mean and median time to the return for reevaluation was calculated with the Kaplan Meier analysis. Glycemias on diagnostic OGTT were correlated to postpartum OGTT using the Spearman correlation test.
Univariate Poisson regression analysis was used to calculate the risk ratio of factors associated to persistent postpartum glucose impaired tolerance. All significant variables in the univariate analyses were included in a robust multivariate Poisson regression.

Statistical analyses were performed with the SPSS software version 18.0 (IBM Company). The significance level used was 0.05 .

\section{RESULTS}

Gestational diabetes was diagnosed by the Brazilian criterion in 183 women; 26 had GDM according to the IADPSG criteria. Of the 209 women, 111 did at least one of the following postpartum tests: only fasting plasma glucose $(\mathrm{n}=14,12.6 \%)$, OGTT $(\mathrm{n}=93,83.8 \%)$, random blood glucose $(\mathrm{n}=2,1.8 \%)$ or Alc test $(\mathrm{n}=1$, $0.9 \%$ ). A subject with a random glucose of $150 \mathrm{mg} / \mathrm{dL}$, one with only the Alc test, and one with an undated FPG were excluded. Another woman included in the analysis had random blood glucose of $350 \mathrm{mg} / \mathrm{dL}$ and was treated at emergency room for symptomatic hyperglycemic decompensation. The return rate for reevaluation was, therefore, of 108 among 209 women (51.7\%; 95\% CI: .45-59).

Clinical characteristics of women who returned and who did not return are shown in table 1. Reevaluation occurred 4 to 734 days postpartum. Median time was 63 days (95\% CI: 60.8-65.2): 10 women $(9.3 \%)$ returned before 6 weeks, $77(72 \%)$ between 6 and 12 weeks, and $9(8.4 \%)$ until 6 months postpartum. The remaining 11 women $(10.3 \%)$ returned more than 180 days after delivery, and, in general, the glucose test was carried out due to a routine evaluation, either by a clinician, a gynecologist, or a surgeon. Return was only associated with lower parity rate $(2 v s .3, \mathrm{p}<0.001)$, and higher pregnancy 2-h OGTT (165 vs. $155 \mathrm{mg} / \mathrm{dL}, \mathrm{p}=0.034$ ).

A significant correlation was found between the OGTT FPG during pregnancy with postpartum FPG $(\mathrm{r}=0.394, \mathrm{p}<0.001)$ and postpartum 2 -h glucose $(\mathrm{r}=$ $0.215, \mathrm{p}=0.038$ ). There was also a positive correlation between the postpartum FPG and the 2-h postpartum glucose $(\mathrm{r}=0.353, \mathrm{p}<0.001)$.

Among the 108 women that were reevaluated, 82 (76\%) had normal postpartum glucose tolerance, while $26(24 \%)$ remained with dysglycemia: $22(20 \%)$ had IFG or IGT and $4(4 \%)$ had diabetes. The main characteristics of the women, according to postpartum reclassification, are displayed in table 2. Previous GDM, a positive 
Table 1. Clinical profile of postpartum returning and non-returning GDM women

\begin{tabular}{|c|c|c|c|}
\hline \multirow{2}{*}{ Characteristic } & Postpartum reevaluation & No postpartum reevaluation & \multirow{2}{*}{$\mathbf{P}$} \\
\hline & $\mathrm{N}=108$ & $N=101$ & \\
\hline $\operatorname{Age}^{1}(y)$ & $32(6)$ & $32(6)$ & 0.565 \\
\hline Pre-pregnancy BMI² (kg/m²) & $28.5[24.1-34.4]$ & $27.9[24.4-33.5]$ & 0.712 \\
\hline Unemployed ${ }^{3}$ & $31(29)$ & $36(35)$ & 0.406 \\
\hline Years in school ${ }^{3}(<8)$ & $29(27)$ & $38(37)$ & 0.168 \\
\hline Socioeconomic level Brazil ${ }^{3}$ (A or B) & $29(37)$ & $18(23)$ & 0.082 \\
\hline Living with a partner ${ }^{3}$ & $79(74)$ & $75(74)$ & $>0.999$ \\
\hline White skin color ${ }^{3}$ & $82(77)$ & $71(70)$ & 0.322 \\
\hline Parity rate $^{2}(\mathrm{n})$ & $2(1-3)$ & $3(2-4)$ & $<0.001$ \\
\hline Family history of $\mathrm{DM}^{3}$ & $62(59)$ & $58(60)$ & $>0.999$ \\
\hline Previous GDM³ & $13(12)$ & $16(16)$ & 0.590 \\
\hline \multicolumn{4}{|l|}{ GDM diagnostic OGTT glucose $(\mathrm{mg} / \mathrm{dL})$} \\
\hline Fasting & $93[86-103]$ & $96[86-110]$ & 0.143 \\
\hline $1-h^{*}$ & $195[165-207.5]$ & 170 [155.5-199] & 0.107 \\
\hline $2-h$ & $165[147-187]$ & $155[146-168]$ & 0.034 \\
\hline Diagnostic A1c test ${ }^{2}(\%)$ & $5.5[5.2-6.0]$ & $5.7[5.3-6.3]$ & 0.122 \\
\hline Pregnancy weight gain² $(\mathrm{kg})$ & $9.2[4.4-13.1]$ & $9.1[5.4-14.4]$ & 0.400 \\
\hline Drug-treated GDM³ & $64(60)$ & $57(60)$ & 0.663 \\
\hline Complications in index pregnancy ${ }^{* *}$ & $49(45.8)$ & $49(49)$ & 0.747 \\
\hline
\end{tabular}

GDM: gestational diabetes mellitus; BMI: body mass index; DM: diabetes mellitus; OGT: oral glucose tolerance test.

${ }^{*} \mathrm{n}=26$; ${ }^{* \star}$ fetal macrosomia, neonatal hypoglycemia or intensive care unit admission, maternal hypertensive disorders.

Results are expressed as: ${ }^{1}$ mean (DP); ${ }^{2}$ median [inter-quartile intervall]; ${ }^{3} \mathrm{n}(\%)$.

Table 2. Clinical and laboratory characteristics of GDM patients according to postpartum glucose test results

\begin{tabular}{|c|c|c|c|c|c|}
\hline \multirow{2}{*}{ Characteristics } & $\begin{array}{c}\text { Normal postpartum } \\
\text { glucose }\end{array}$ & $\begin{array}{l}\text { Abnormal postpartum } \\
\text { glucose }\end{array}$ & \multirow[t]{2}{*}{$\mathbf{P}$} & Relative risk ${ }^{\mathbf{a}}$ & \multirow[t]{2}{*}{$\mathbf{P}$} \\
\hline & $(n=82)$ & $(n=26)$ & & RR (95\% Cl) & \\
\hline $\operatorname{Age}^{2}(y)^{*}$ & $31.2[27-35]$ & $35[29-39]$ & 0.144 & $1.04(0.97-1.12)$ & 0.227 \\
\hline Pre-gestational BMI² (kg/m²) & $28.2[23.3-34.5]$ & $28.5[26.3-33.8]$ & 0.448 & $1.01(0.97-1.1)$ & 0.56 \\
\hline Previous GDM ${ }^{3}$ & $5(6)$ & $8(31)$ & 0.002 & $3.25(1.78-5.90)$ & $<0.001$ \\
\hline Family history of $\mathrm{DM}^{3}$ & $42(52)$ & $21(81)$ & 0.017 & $2.94(1.20-7.19)$ & 0.019 \\
\hline Fasting glucose - GDM diagnosis 0GTT² (mg/dL)* & $91[84-102]$ & $102.5[94-112]$ & $<0.001$ & $1.012(1.009-1.015)$ & $<0.001$ \\
\hline 2-h glucose - GDM diagnosis OGT² $(\mathrm{mg} / \mathrm{dL})^{*}$ & $158[145-179]$ & $184.5[161-195]$ & 0.004 & $1.015(1.008-1.022)$ & $<0.001$ \\
\hline A1c - GDM diagnosis ${ }^{2}(\%)^{*}$ & $5.5[5.1-5.9]$ & $6.0[5.2-6.6]$ & 0.045 & $1.49(1.22-1.82)$ & $<0.001$ \\
\hline $\mathrm{HOMA}^{2}$ * & $2.7[1.9-4.1]$ & $4.3[3.1-5.4]$ & 0.017 & $1.16(1.02-1.32)$ & 0.023 \\
\hline Drug treated $\mathrm{GDM}^{3}$ & $44(54)$ & $21(81)$ & 0.026 & $2.78(1.13-6.8)$ & 0.025 \\
\hline Insulin treated GDM³ & $9(11)$ & $12(46)$ & $<0.001$ & $3.55(1.94-6.51)$ & $<0.001$ \\
\hline Weight gain in pregnancy² & $7.2[3.9-10.9]$ & $5.0[2.8-8.5]$ & 0.149 & $0.96(0.91-1.02)$ & 0.232 \\
\hline Complications in index pregnancy $3 \S$ & $32(39)$ & $18(69)$ & 0.014 & $2.61(1.24-5.48)$ & 0.011 \\
\hline Cesarean section ${ }^{3}$ & $39(47.6)$ & $19(73.1)$ & 0.041 & $2.34(1.07-5.10)$ & 0.033 \\
\hline Fasting glucose - postpartum OGTT2 (mg/dL) & $87[84-92]$ & $105[99-117]$ & $<0.001$ & $1.008(1.006-1.01)$ & $<0.001$ \\
\hline 2-h glucose - postpartum OGTT² (mg/dL) & $93[84-108]$ & $151[124-191]$ & $<0.001$ & $1.006(1.004-1.009)$ & $<0.001$ \\
\hline
\end{tabular}

GDM: gestational diabetes mellitus; BMI: body mass index; DM: diabetes mellitus; OGTT: oral glucose tolerance test; HOMA-IR: homeostasis model assessment - insulin resistance.

Results are expressed as: ${ }^{1}$ mean (DP); ${ }^{2}$ median [inter-quartile interval]; ${ }^{3} \mathrm{n}(\%)$.

* at GDM diagnosis in index pregnancy.

$\S$ fetal macrosomia, neonatal hypoglycemia or intensive care unit admission, hypertensive disorders.

a "no presence" is the reference category. 
family history of diabetes, higher glucose levels on the diagnostic OGTT, higher Alc test, higher plasma insulin and HOMA, as well as the need of medication to control GDM, and higher rate of pregnancy complications and cesarean section were found in the group with persistent hyperglycemia. Other possible risk factors, such as triglycerides and height $<151 \mathrm{~cm}$ were analyzed, but were not different between the two groups.

The final multivariate model showed sustained significance for a positive family history of diabetes (relative risk - RR 2.4l, $\mathrm{p}=0.050$ ), the 2 -h glucose value on the diagnostic OGTT (RR 1.01, p = 0.045), the need of insulin in pregnancy ( $R R 2.37, \mathrm{p}=0.014)$, and cesarean section ( $R R 2.61, \mathrm{p}=0.015$ ) as predictors of persistent postpartum hyperglycemia (Table 3 ).

Table 3. Risks factors for persistent postpartum hyperglycemia multivariate analysis

\begin{tabular}{lcc}
\hline Characteristic (independent variable) & RR (95\% CI) & p \\
\hline Family history of diabetes & $2.41(1.00-5.80)$ & 0.050 \\
2-h glucose - GDM diagnostic OGTT & $1.01(1.00-1.02)$ & 0.045 \\
Insulin use & $2.37(1.19-4.70)$ & 0.014 \\
Cesarean section & $2.61(1.21-5.66)$ & 0.015 \\
\hline
\end{tabular}

\section{DISCUSSION}

In this prospective cohort of 209 GDM women, the rate of return for postpartum reevaluation was $51.7 \%$; women who returned had lower parity rate and higher 2 -h value on diagnostic 75-g OGTT, and were retested as recommended by official positions. Characteristics associated to the persistence of dysglycemia after pregnancy were family history of diabetes, some metabolic alterations in the third trimester of pregnancy, and the need for cesarean section in the index pregnancy.

Since the first studies by O'Sullivan describing estimated incidence of type 2 diabetes of up to $52 \%$ in a period of 6 to 7 years after a GDM pregnancy (17), special concerns on follow-up strategies of these women were raised. The concept that GDM represents previously undiagnosed impaired glucose tolerance that is uncovered by active search during pregnancy, and the presence of risk factors associated with type 2 diabetes (18) corroborate the need of postpartum reevaluation. In a systematic review including 20 cohort studies, a seven-fold risk of presenting type 2 diabetes in the future was found in the presence of previous GDM preg- nancy (19). In a reevaluation after 4 to 8 years of the index pregnancy in a Brazilian cohort, the risk of developing any glucose alteration was 1.9 higher in women with GDM pregnancy compared with normal glucose tolerant pregnant women (20). Irrespective of gestational diabetes being a risk factor, a stage of the natural history of type 2 diabetes, or a pre-existing alteration disclosed during pregnancy, postpartum reevaluation is mandatory and is advocated by endocrine and obstetric organizations, due to the possibility of early diagnosis and treatment of the metabolic alteration $(21,22)$.

Nevertheless, despite traditional recommendation for postpartum testing, the rates of return are still low and vary across different studies, depending on population characteristics. Spontaneous return may be of $64.2 \%$ in the first three months postpartum (raw average $35 \%$ ), whereas active search (reminder calls and other tools) is associated with a $92.6 \%$ rate (raw average $64.8 \%$ ) (7). Our study disclosed a little more than half percent of spontaneous return, with more than $70 \%$ of women being tested in the recommended 6 to 12 week postpartum period. However, this may be considered a low rate of retesting, since these women were participating in a cohort study and had received prenatal care in a University hospital. Surprisingly, our rate is only slightly higher than the one found in a Brazilian cohort of women in the same region $(42 \%)$ more than 10 years ago (23); and very similar to the one described in a large retrospective American cohort (50.2\%) (8). Reevaluation in 4 to 8 years after a GDM pregnancy in Brazilian women disclosed rates of return of $74 \%$ for those with glucose alterations in pregnancy, and of $50 \%$ for those with normal glucose tolerance $(20)$. In the present study, almost $20 \%$ of those returning did it after the recommended period. Rates of return after the 3 first months postpartum in other studies are similar to $30 \%$, rising to around $60 \%$ with active search $(7)$. In one of the largest studies, only $46 \%$ of the women were retested in the recommended period (8).

Return rate was associated with race, older age, null parity rate, and higher income or education in a recent systematic review (24), contrasting with our results: we did not find any social or economical variable associated with reevaluation. In our study, return was associated with lower parity rate, suggesting that planning a future pregnancy may be an important stimulus for reevaluation. Higher parity rate was also associated to lack of adherence in a Canadian study with a similar return rate (48\%) (9). As expected, having a higher 2 -h value in pregnancy OGTT 
was associated with higher rates of return, as found in the present cohort, since women are generally aware of the risk of developing type 2 diabetes after having a GDM diagnosis (25). Surprisingly, complications in index pregnancy, such as fetal macrosomia, neonatal hypoglycemia, or ICU admission, and maternal hypertensive disorders were not related with a higher rate of returning, meaning that even complicated pregnancies were not enough to alarm these women about future risks.

Strategies to increase return for evaluation include, besides routine counseling during pregnancy and at delivery, making reminder calls to patients after the medical staff is informed by an electronic system that the scheduled return was not met (26). In our study, a remind call would benefit not only the $48.3 \%$ women who did not return to postpartum testing, but also the $20 \%$ that came after 6 months of the delivery. Central hospital reminder calls were associated with a $82.5 \%$ return rate in a Finnish study (27). Routine care after delivery provided by obstetricians and family physicians, although frequent, did not improve rates of testing and was considered a "missed opportunity" by some authors (28). Active and systematic actions to improve compliance and return must be optimized by the medical staff, since they can potentially double reevaluation rates $(7)$.

A high rate of postpartum glucose alteration was found in our study (24.1\%), mainly IGT and IFG (20.4\%). In studies from 1990 to 2012 that described the initial 12 week postpartum return, reported rates ranged from $2.2 \%$ to $42.3 \%$ for either IGT or IGF, and from 1 to $16 \%$ for diabetes, depending on the population characteristics and the criteria that defined the metabolic alteration (7). In the large cohort by Lawrence and cols. (8), 16.3\% had IFG or IGT and only 1.1\% had diabetes, an incidence slightly lower than ours. Persistent glucose alteration was associated with maternal age, race, education, income, parity and pharmacological GDM treatment (8). As in our cohort, family history of diabetes, glucose values in the diagnostic test and insulin use in pregnancy were predictors of a nine-fold increase in type 2 diabetes rates 15 years after GDM in an Australian retrospective cohort (11). A "metabolic syndrome-like cluster in pregnancy" with specific thresholds for BMI, insulin triglycerides, HDL-cholesterol and systolic blood pressure measured in GDM women was reported as a good predictor of type 2 diabetes development 10 years after the index pregnancy (29).
Although Alc is not a recommended test for GDM diagnosis, it was routinely measured in our cohort and was a significant predictor of persistent glucose alteration. The association of metabolic derangement at diagnosis to glucose impairment after pregnancy, either considering the Alc test or the glucose diagnostic values, was described in other studies $(9,11,30)$. Maternal and neonatal complications and delivery by cesarean section in the index pregnancy more than doubled the risk of postpartum glycemic alteration in univariate analysis, certainly due to their association with the presence of more severe hyperglycemia during pregnancy. The effect of maternal complications disappeared in multivariate analysis.

As expected, family history of diabetes and the severity of GDM, especially when insulin was used, were important predictors of future glucose alterations.

Another issue concerning postpartum reevaluation is which test should be performed. Official recommendations suggest either the FPG or OGTT. Fasting plasma glucose or even the Alc test would be more feasible and comfortable for the women, and could potentially increase return rates. In our cohort, although fasting glucose measured during the postpartum OGTT was significantly correlated with the 2 -h glucose measurement, the correlation was weak and precludes its recommendation as the sole tool for reclassification. In a systematic review of 13 studies comparing the FPG to the OGTT performance for the postpartum reevaluation of GDM women, FPG lacked sensitivity as a screening test (31).

Our study has an important methodological strength over previous studies, since it is a prospective cohort. Our data about pregnancy variables and socioeconomic characteristics of participants were collected during the beginning of the third trimester. Moreover, our study results had a broad external validity because we evaluated all women who had been referred to our high-risk prenatal care. One possible limitation of the study is that we enrolled women labeled as gestational diabetes both by the Brazilian and the IADPSG/ADA criteria, since the discussion on GDM diagnostic procedures still remains a matter of great controversy $(5,6,32,33)$. Another possible limitation is that the frequency of impaired glucose we found may be overestimated due to more frequent return of GDM women with higher 2-h glucose values on the diagnostic OGTT.

In conclusion, the return rate for postpartum reevaluation was low, but glucose alterations were frequently 
found in retested women of this Brazilian GDM cohort. Reminder calls or other actions for postpartum glucose reassessment are highly recommended, particularly for women with a family history of GDM or who had a more severe GDM presentation, since these women are at increased risk of persistent hyperglycemia after pregnancy.

Acknowledgments: we would like to thank Renata Castro Rodrigues for her help in preparing the manuscript.

Funding: this study was funded by Fundo de Incentivo à Pesquisa e Eventos (FIPE), Hospital de Clínicas de Porto Alegre.

Disclosure: no potential conflict of interest relevant to this article was reported.

\section{REFERENCES}

1. Dabelea D, Snell-Bergeon JK, Hartsfield CL, Bischoff KJ, Hamman RF, McDuffie RS, et al. Increasing prevalence of gestational diabetes mellitus (GDM) over time and by birth cohort: Kaiser Permanente of Colorado GDM Screening Program. Diabetes Care. 2005;28(3):579-84.

2. Sacks DA, Hadden DR, Maresh M, Deerochanawong C, Dyer AR, Metzger $B E$, et al. Frequency of gestational diabetes mellitus at collaborating centers based on IADPSG consensus panelrecommended criteria: the Hyperglycemia and Adverse Pregnancy Outcome (HAPO) Study. Diabetes Care. 2012;35(3):526-8.

3. Prevention $\mathrm{CfDCa}$. Obesity and overweight for professionals: data and statistics: adult obesity - DNPAO - CDC [cited 2013 September 29]. Available at: http://www.cdc.gov/obesity/data/adult.html].

4. Kim C, Newton KM, Knopp RH. Gestational diabetes and the incidence of type 2 diabetes: a systematic review. Diabetes Care. 2002;25(10):1862-8.

5. Practice bulletin no. 137: gestational diabetes mellitus. Obstet Gynecol. 2013;122(2 Pt 1):406-16.

6. American Diabetes Association. Standards of medical care in diabetes--2013. Diabetes Care. 2013;36 Suppl 1:S11-66.

7. Carson MP, Frank MI, Keely E. Original research: postpartum testing rates among women with a history of gestational diabetesSystematic review. Prim Care Diabetes. 2013;7(3):177-86.

8. Lawrence JM, Black MH, Hsu JW, Chen W, Sacks DA. Prevalence and timing of postpartum glucose testing and sustained glucose dysregulation after gestational diabetes mellitus. Diabetes Care. 2010;33(3):569-76.

9. Kwong S, Mitchell RS, Senior PA, Chik CL. Postpartum diabetes screening: adherence rate and the performance of fasting plasma glucose versus oral glucose tolerance test. Diabetes Care. 2009;32(12):2242-4

10. Löbner K, Knopff A, Baumgarten A, Mollenhauer U, Marienfeld S, Garrido-Franco M, et al. Predictors of postpartum diabetes in women with gestational diabetes mellitus. Diabetes. 2006;55(3):792-7.

11. Lee AJ, Hiscock RJ, Wein P, Walker SP, Permezel M. Gestational diabetes mellitus: clinical predictors and long-term risk of developing type 2 diabetes: a retrospective cohort study using survival analysis. Diabetes Care. 2007;30(4):878-83.
12. Reichelt AJ OM, Schmidt MI. Recomendações da $2^{\mathrm{a}}$ Reunião do Grupo de Trabalho em Diabetes e Gravidez. Arq Bras Endocrinol Metab. 2002;46:574-81.

13. Metzger BE, Gabbe SG, Persson B, Buchanan TA, Catalano $\mathrm{PA}$, Damm $\mathrm{P}$, et al. International Association of Diabetes and Pregnancy Study Groups recommendations on the diagnosis and classification of hyperglycemia in pregnancy. Diabetes Care. 2010;33(3):676-82.

14. Pesquisa ABdEd. Critério de Classificação Econômica Brasil. 2008 [cited 2009]. Available at: http://www.abep.org/novo/Content. aspx?ContentID=139].

15. Report of the National High Blood Pressure Education Program Working Group on High Blood Pressure in Pregnancy. Am J Obstet Gynecol. 2000;183(1):S1-S22.

16. Matthews DR, Hosker JP, Rudenski AS, Naylor BA, Treacher DF, Turner RC. Homeostasis model assessment: insulin resistance and beta-cell function from fasting plasma glucose and insulin concentrations in man. Diabetologia. 1985;28(7):412-9.

17. O'Sullivan JB. Diabetes mellitus after GDM. Diabetes. 1991;40 Suppl 2:131-5.

18. Harris MI. Gestational diabetes may represent discovery of preexisting glucose intolerance. Diabetes Care. 1988;11(5):402-11.

19. Bellamy L, Casas JP, Hingorani AD, Williams D. Type 2 diabetes mellitus after gestational diabetes: a systematic review and metaanalysis. Lancet. 2009;373(9677):1773-9.

20. Jacob Reichelt AA, Ferraz TM, Rocha Oppermann ML, Costa e Forti A, Duncan BB, Fleck Pessoa E, et al. Detecting glucose intolerance after gestational diabetes: inadequacy of fasting glucose alone and risk associated with gestational diabetes and second trimester waist-hip ratio. Diabetologia. 2002;45(3):455-7.

21. Ratner RE, Christophi CA, Metzger BE, Dabelea D, Bennett PH, Pi-Sunyer $X$, et al. Prevention of diabetes in women with a history of gestational diabetes: effects of metformin and lifestyle interventions. J Clin Endocrinol Metab. 2008;93(12):4774-9.

22. Hu G, Tian H, Zhang F, Liu H, Zhang $C$, Zhang $S$, et al. Tianjin Gestational Diabetes Mellitus Prevention Program: study design, methods, and 1-year interim report on the feasibility of lifestyle intervention program. Diabetes Res Clin Pract. 2012;98(3):508-17.

23. Seligman LLB. Preditores clínicos para diabetes mellitus pós-parto em mulheres com diabetes gestacional recente. Arq Bras Endocrinol Metab. 2001;47(5 (supl 1)):P081.

24. Tovar A, Chasan-Taber L, Eggleston E, Oken E. Postpartum screening for diabetes among women with a history of gestational diabetes mellitus. Prev Chronic Dis. 2011;8(6):A124.

25. Zera CA, Nicklas JM, Levkoff SE, Seely EW. Diabetes risk perception in women with recent gestational diabetes: delivery to the postpartum visit. J Matern Fetal Neonatal Med. 2013;26(7):691-6.

26. Vesco KK, Dietz PM, Bulkley J, Bruce FC, Callaghan WM, England $L$, et al. A system-based intervention to improve postpartum diabetes screening among women with gestational diabetes. Am J Obstet Gynecol. 2012;207(4):283.e1-6.

27. Korpi-Hyövälti E, Laaksonen DE, Schwab U, Heinonen S, Niskanen L. How can we increase postpartum glucose screening in women at high risk for gestational diabetes mellitus? Int $\mathrm{J}$ Endocrinol. 2012;2012:519267.

28. Shah BR, Lipscombe LL, Feig DS, Lowe JM. Missed opportunities for type 2 diabetes testing following gestational diabetes: a population-based cohort study. BJOG. 2011;118(12):1484-90.

29. Barden A, Singh R, Walters B, Phillips M, Beilin LJ. A simple scoring method using cardiometabolic risk measurements in 
pregnancy to determine 10-year risk of type 2 diabetes in women with gestational diabetes. Nutr Diabetes. 2013;3:e72.

30. Sivaraman SC, Vinnamala S, Jenkins D. Gestational diabetes and future risk of diabetes. J Clin Med Res. 2013;5(2):92-6.

31. Bennett WL, Bolen S, Wilson LM, Bass EB, Nicholson WK. Performance characteristics of postpartum screening tests for type 2 diabetes mellitus in women with a history of gestational diabetes mellitus: a systematic review. J Womens Health (Larchmt). 2009;18(7):979-87.

32. Coustan DR. Gestational diabetes mellitus. Clin Chem. 2013;59(9):1310-21.

33. Hadar E, Yogev Y. Translating the HAPO study into new diagnostic criteria for GDM? From HAPO to IADPSG and back to O'Sullivan. Clin Obstet Gynecol. 2013;56(4):758-73. 